\title{
Preliminary investigation of acaricidal activity of leaf extract of Nicotiana tabacum on dog tick Rhipicephalus sanguineus
}

\author{
Taiwo Olaide Oyagbemi ${ }^{1}$, Anofi Ashafa ${ }^{2}$, Johnson Olayide Adejinmi ${ }^{1}$ and Oluwafemi Omoniyi Oguntibeju ${ }^{3}$
}

1. Department of Veterinary Parasitology and Entomology, Faculty of Veterinary Medicine, University of Ibadan, Nigeria; 2. Faculty of Natural and Agricultural Sciences, Qwaqwa Campus, University of the Free State, Phuthaditjhaba, South Africa; 3. Phytomedicine and Phytochemistry Group, Department of Biomedical Sciences, Faculty of Health and Wellness Sciences, Cape Peninsula University of Technology, Bellville 7535, South Africa. Corresponding author: Taiwo Olaide Oyagbemi, e-mail: akantai2018@gmail.com

Co-authors: AA: ashafaaot@ufs.ac.za, JOA: olaadejinmi@yahoo.co.uk, ooo: oguntibejuo@cput.ac.za Received: 08-05-2019, Accepted: 03-09-2019, Published online: 25-10-2019

doi: www.doi.org/10.14202/vetworld.2019.1624-1629 How to cite this article: Oyagbemi TO, Ashafa A, Adejinmi JO, Oguntibeju OO (2019) Preliminary investigation of acaricidal activity of leaf extract of Nicotiana tabacum on dog tick Rhipicephalus sanguineus, Veterinary World, 12(10): 1624-1629.

\begin{abstract}
Background and Aim: Tick infestation of domestic animals remains a major constraint to livestock productivity across all agro-ecological zones most especially in small animal practice. The most common method of tick control is the use of synthetic acaricide. However, a widespread increase of acaricidal resistance, scarcity and high cost of acaricides especially to farmers of low-income earnings in developing countries support the need for alternative tick control methods. Among the alternative methods for tick control is herbal therapy. In this study, we investigated the acaricidal activity of methanol and N-hexane leaf extracts of Nicotiana tabacum against dog ticks - Rhipicephalus sanguineus.
\end{abstract}

Materials and Methods: Larvicidal and adulticidal activity of $N$. tabacum leaf extract were examined on the dog tick $R$. sanguineus in an in vitro experiment using larval packet test and adult immersion test respectively. Phytochemical and Gas Chromatography-Mass Spectrometry (GC-MS) analysis of the leaf extract were also carried out using standard methods.

Results: We observed a tick mortality rate that was concentration-dependent. However, N-hexane extract showed a higher significant acaricidal effect than methanol extract. Lethal dose $\left(\mathrm{LD}_{50}\right)$ of $N$. tabacum was 0.06 . High quantity of terpenoids was obtained from $N$. tabacum. Lower tick glutathione S-transferase observed with varying concentration of $N$. tabacum. GC-MS revealed Pyridine, 3-(1-methyl-2-pyrrolidinyl)-, (S) - Nicotine, Citronellyl propionate, Crotonaldehyde, Lavandulyl acetate, trans-Phytol and Amitrole (3-Amino-1, 2, 4-triazole) in N. tabacum.

Conclusion: Both methanol and N-hexane leaf extracts of $N$. tabacum exhibited observable acaricidal property against the larvae and adult $R$. sanguineus of dog.

Keywords: adulticidal, ethnoveterinary, larvicidal, Nicotiana tabacum, Rhipicephalus sanguineus.

\section{Introduction}

Chemical control with synthetic acaricides is considered one of the best methods so far, although, ticks have developed resistance against a great number of these chemical acaricides [1]. Controlling of ticks is imperative due to their ability to transmit more pathogenic organisms compared to other arthropod vectors [2]. Great economic loss ranging from low productivity, mortality, and direct effect of tick burden has been attributed to tick infestation [3]. A number of tick resistances to synthetic acaricides have been reported by many researchers [4].

Biodegradability, low toxicity to the environment, and non-targeted species coupled with ready availability of some botanical acaricides give it an advantage over synthetic acaricides [5]. So far,

Copyright: Oyagbemi, et al. Open Access. This article is distributed under the terms of the Creative Commons Attribution 4.0 International License (http://creativecommons.org/licenses/ by/4.0/), which permits unrestricted use, distribution, and reproduction in any medium, provided you give appropriate credit to the original author(s) and the source, provide a link to the Creative Commons license, and indicate if changes were made. The Creative Commons Public Domain Dedication waiver (http:// creativecommons.org/publicdomain/zero/1.0/) applies to the data made available in this article, unless otherwise stated. promising results have been obtained from some plants screened for anti-tick properties. Among the natural products, plant extracts and essential oils have shown high significant activity against all the stages of economically important tick species [6]. Plant essential oils have been reported to show ovicidal, larvicidal, pupicidal, adulticidal and repellant activities against Rhipicephalus species of tick [7]. Insecticidal and acaricidal activities of neem products have also been reported [8]. Tephrosia vogelii, Ricinus communis, and essential oils of Syzygium aromaticum gave a satisfactory result on engorged females of Rhipicephalus spp. [9-11]. The involvement of different mixtures of biological compounds in herbal therapy helps to checkmate resistance development [12]. Dipeolu and Ndungu [13] reported an accidental acaricidal effect of leaves of Nicotiana tabacum on adult female Rhipicephalus spp. Mangifera indica [14] and Azadirachta indica [15] have also been reported to possess acaricidal activity.

For the purpose of this study, we explored the acaricidal potential of the leaves of $N$. tabacum. It belongs to Solanaceae family, which includes crop species such as tomatoes, potatoes, and peppers [16]. Nicotine 
plant has more than 60 species, among which only Nicotiana rustica and N. tabacum are widely used by humans. Here, we investigated the acaricidal activity of methanol and N-hexane leaf extracts of $N$. tabacum against dog ticks Rhipicephalus sanguineus.

\section{Materials and Methods}

\section{Ethical approval}

This study was approved by the Animal Care and Use Research Ethics Committee, University of Ibadan, Nigeria (UI-ACUREC/App/17/0031).

\section{Plant material}

Plants of $N$. tabacum were randomly collected from different geographical locations of the study area within Ibadan Metropolis from October 2016 to March 2017. The plant was authenticated in the Department of Botany, University of Ibadan, Oyo State, Nigeria, and kept as herbarium specimen with a voucher number UIH-22634.

\section{Preparation of extracts}

The leaves were collected in the dry season, shade dried at room temperature for 2 weeks. The dried leaves were pulverized using a grinder. The powdered leaf material $(3 \mathrm{~kg})$ was cold extracted using $10 \mathrm{~L}$ each of methanol and N-hexane for $72 \mathrm{~h}$ and then concentrated with rotary vacuum evaporator. The extracts which were semi-solid forms were completely dried at room temperature. Different quantity of extracts was weighed and dissolved in seven different dilutions of dimethyl sulfoxide (DMSO) at the rate of $0.04,0.05,0.06,0.07,0.08,0.09$, and $0.10 \mathrm{mg} / \mathrm{ml}$ serial dilution. About 16\% diazinon (DZN) (organophosphate) served as a positive control and DMSO as a negative control.

\section{Collection of ticks}

A total of 600 fully engorged adult female ticks $R$. sanguineus were collected from different naturally infested adult dogs brought to University of Ibadan, Veterinary Teaching Hospital with a history of no recent exposure to any acaricide. Maximum of 10 adult female ticks were collected from each infested dog. Ticks were harvested from selected predilection sites with the aid of blunt pointed forceps to avoid any harm to ticks and hosts. Ticks were collected into Bijou Bottles and labeled with details of animals such as sex, breed, age and date of collection. The ticks were reproduced to obtain the larva for larval immersion test. It was not a pooled sample. The collected ticks were singly morphologically identified using taxonomic keys [17].

\section{Sub-acute toxicity test}

Sub-acute toxicity test was conducted according to the Organization for Economic Co-operation and Development guidelines [18]. Group A received a body spray of $0.05 \mathrm{mg} / \mathrm{ml}$ DMSO; Group B received $0.05 \mathrm{mg} / \mathrm{ml}$ body spray of $16 \%$ DZN. Groups C, $\mathrm{D}$ and $\mathrm{E}$ received body spray of $0.04,0.06$, and $0.08 \mathrm{mg} / \mathrm{ml}$ of both methanol and N-hexane leaves extract of $N$. tabacum separately. The rats were exposed once a week for 3 consecutive weeks. The animals were observed daily for any sign of toxicity physically and grossly such as skin reaction, loss of appetite, lacrimation, convulsion, diarrhea and mortality.

\section{Adult immersion test (AIT)}

The effects of adulticidal activity on the ticks were examined in an in vitro experiment. Different concentrations of leaf extracts of the plant $N$. tabacum were evaluated on the ticks collected from natural infested dogs. There were seven groups $(0.04,0.05$, $0.06,0.07,0.08,0.09$, and $0.10 \mathrm{mg} / \mathrm{ml}$ serial dilution) containing 10 ticks in each group. The pour-on method was used as described [19]. Organophosphate and DMSO served as positive and negative control group, respectively. The seven groups each of 10 adult female $R$. sanguineus ticks were weighed and dipped in the respective dilutions for $10 \mathrm{~min}$. After immersion, the ticks were placed in separate Petri dishes and kept in a desiccator maintained at $25^{\circ} \mathrm{C}$ and $80 \%$ relative humidity. The mortality of ticks in all groups was recorded after $30 \mathrm{~min}, 1 \mathrm{~h}, 2 \mathrm{~h}, 4 \mathrm{~h}$, and $6 \mathrm{~h}$ with respect to the movement of Malpighian tubule and dark coloration of the larva. The test for every dilution was in triplicates.

\section{Larval packet test}

Various dilutions $(0.04,0.05,0.06,0.07,0.08$, 0.09 , and $0.10 \mathrm{mg} / \mathrm{ml}$ ) of $N$. tabacum leaf extracts were prepared in a vehicle (DMSO) and the mixture was dispensed on a piece of filter paper separately for each dilution. The filter paper was folded to form a packet and contained 10 (14 days old) larvae of $R$. sanguineus obtainable from hatched eggs of matured female ticks collected. 7-14-day larvae have been reported previously used and at day 14, seed ticks were already developed into larva when observed under microscope. The packets were incubated with $\mathrm{CO}_{2}$ under airtight condition at $25^{\circ} \mathrm{C}$ and $80 \%$ relative humidity within exposure time of $24 \mathrm{~h}$. Under natural condition, the larval stage is easily destroyed following adverse environmental condition, within $24 \mathrm{~h}$; more than $80 \%$ of the larvae were dead both in nicotine-treated and DZN-treated group. Alive and dead larvae were counted [19]. All the experiments were carried out in three replicates (larval and adult stage of ticks).

Determination of acaricide resistance using tick glutathione S-transferase (GST) activity

The tick GST activity was determined [20]. $10 \mu \mathrm{L}$ of tick supernatant and $140 \mu \mathrm{L}$ of phosphate buffer saline, then, $10 \mu \mathrm{L}$ of GSH, add $50 \mu \mathrm{L}$ of 1 -chloro, 2,4-dinitrobenzol. The absorption increase at the new wavelength of $340 \mathrm{~nm}$ provides a direct measurement of the enzymatic reaction.

\section{Gas chromatography-mass spectrometry (GC-MS) of the essential oil of $N$. tabacum}

The essential oil of $N$. tabacum was analyzed using GC-MS (Agilent Technologies, Palo Alto, CA, USA) 5973 Network selective detector with column 
DB23 model number J and W 1222362 with internal diameter of $60 \mathrm{~m} \times 250 \mu \mathrm{m} \times 0.25 \mu \mathrm{m}\left(250^{\circ} \mathrm{C}\right.$ Max $)$. $50 \mu \mathrm{L}$ of the methanol extract of $N$. tabacum was dispensed into $1 \mathrm{ml}$ sample vial and diluted to $1 \mathrm{ml}$ with methanol. The flow rate of $1 \mathrm{ml} / \mathrm{min}$ was used with column flow of $0.57 \mathrm{ml} / \mathrm{min}$ under $50^{\circ} \mathrm{C} \mathrm{GC}$ temperature. The total runtime was $37 \mathrm{~min}$.

\section{Statistical analysis}

The one-way ANOVA and Turkey's multiple comparison tests were carried out using GraphPad Prism version 5 for Windows (GraphPad, San Diego, CA). The results were expressed as means \pm standard error of mean and the level of significant difference between the control group and the treated groups was determined. The median lethal dose $\left(\mathrm{LD}_{50}\right)$ value was statistically calculated from mortality data [21].

\section{Results}

Toxicity test: There was no sign of toxicity (skin bruise, irritation, salivation, incoordination, ataxia, and mortality) in the treated group.

\section{Phytochemical analysis}

The phytochemical analysis on the methanol leaf extract of $N$. tabacum revealed the presence of saponins, tannins, alkaloids, flavonoids and anthraquinones. A relatively high proportion of terpenoids was obtained from the extract while cardiac glycosides and steroids were absent as shown in Table-1.

\section{Percentage mortality of larvae}

The effects of different concentrations of methanol and N-hexane extract of $N$. tabacum on larvae of $R$. sanguineus are shown in Figure-1. Hexane extracts of $N$. tabacum on $R$. sanguineus larvae gave percentage mortality of $99.3 \%$ at a dose concentration of $0.07 \mathrm{mg} / \mathrm{ml}$ while methanol extracts of the same plant gave the same percentage mortality rate of larvae at a higher concentration of $0.10 \mathrm{mg} / \mathrm{ml}$.

\section{AIT}

The result of the AIT using - N-hexane and methanol leaf extracts of $N$. tabacum is shown in Figure-2. Treatment with organophosphate at $0.05 \mathrm{mg} / \mathrm{ml}$ caused $4.5 \%$ adult tick mortality and inhibition of fecundity of $79.4 \%$, respectively. The mortality of the engorged adult female ticks, inhibition of fecundity and hatching of eggs were concentration-dependent. The percentage adult female tick mortality varied from $3.67 \%$ to $8.87 \%$ in methanol extract and $4.33 \%$ to $9.33 \%$ in
$\mathrm{N}$-hexane extract when tested at concentrations ranging from 0.04 to $0.10 \mathrm{mg} / \mathrm{ml}$. The percentage inhibition of fecundity ranged from $25.4 \%$ to $92.1 \%$ in methanol treated extract and $25.4 \%$ to $95.2 \%$ in $\mathrm{N}$-hexane treated extracts, respectively. The degree of mortality is directly proportional to increase in concentration.

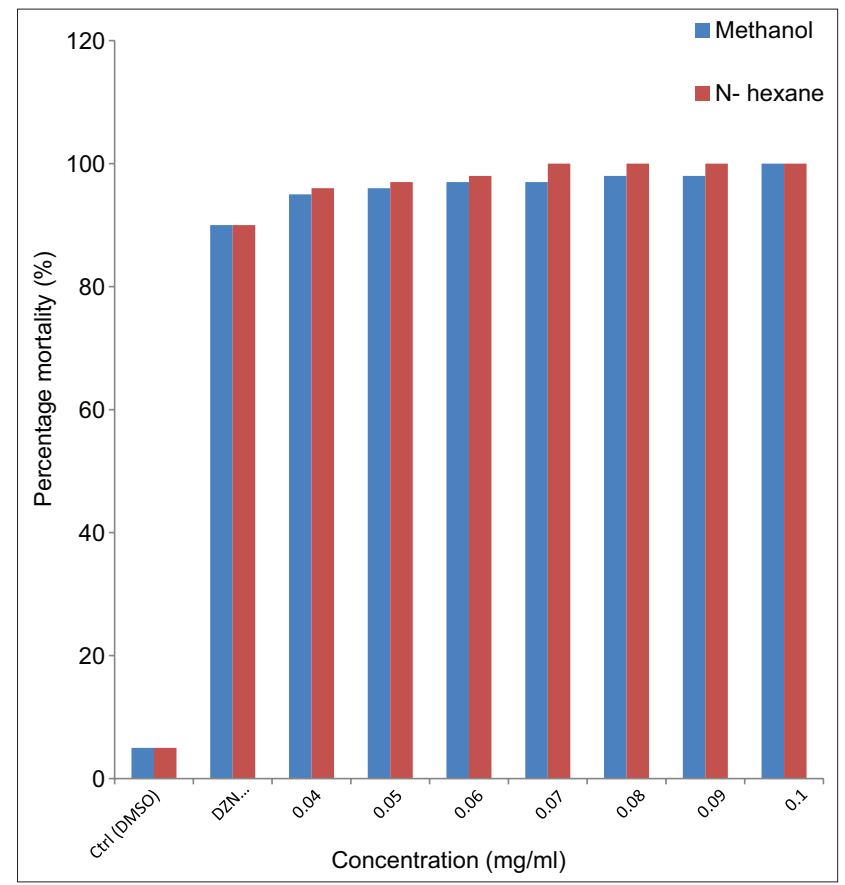

Figure-1: Effect of leaf extract of Nicotiana tabacum on percentage mortality of the larval stage of Rhipicephalus sanguineus.

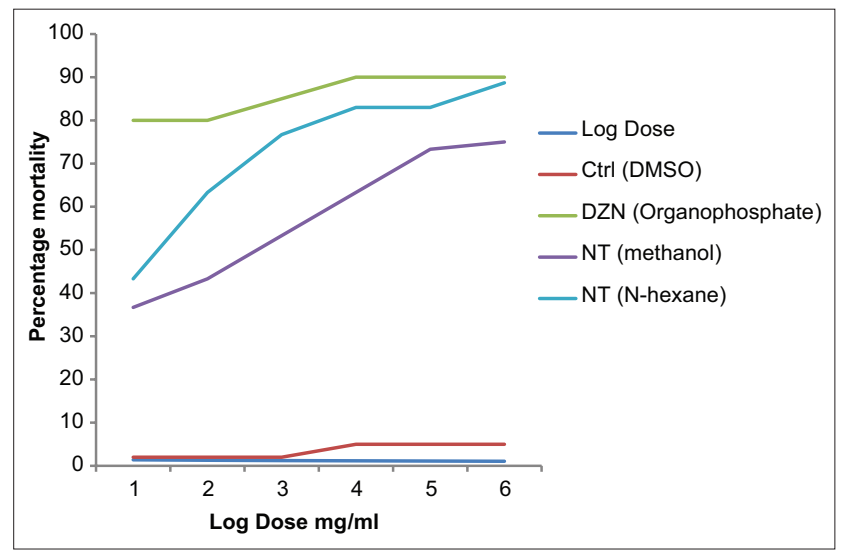

Figure-2: Effect of leaf extract of Nicotiana tabacum on percentage mortality of female adult Rhipicephalus sanguineus.

Table-1: Phytochemical analysis of Nicotiana tabacum.

\begin{tabular}{|c|c|c|}
\hline Phytochemical constituents & Nicotiana tabacum (Methanol extract) & Nicotiana tabacum ( $\mathrm{N}-\mathrm{hexane}$ extract) \\
\hline Saponins & + & + \\
\hline Tannis & + & + \\
\hline Alkaloids & + & ++ \\
\hline Cardiac glycosides & _- & + \\
\hline Flavonoids & $\overline{+}$ & + \\
\hline Terpenoids & + & ++ \\
\hline Anthraquinones & + & + \\
\hline Steroid & _- & + \\
\hline
\end{tabular}




\section{Acaricidal resistance}

GST activity in the tick increased significantly in the DZN-treated group compared to the control and other treatment groups (NT1-NT3) (Figure-3). However, treatment with NT1 and NT2 showed a significant reduction in the activity of tick GST in a dose-dependent manner. The higher the GST activity, the higher the rate of resistance development.

\section{GC-MS analysis}

The GC-MS analysis of the essential compound detected from N. tabacum includes Pyridine, 3-(1-methyl-2-pyrrolidinyl)-, (S)-Nicotine, 2-Methyl-4, 5-dihydrofuran, Neophytadiene, trans-Phytol, Citronellyl propionate, Lavandulyl acetate, Bicyclo (4.1.0)heptane,3-methyl,2,3,4,5-Tetrahydropyridazine, Crotonaldehyde, 3-Amino-1,2,4-triazole (Amitrole), and 4-Acetoxy-tetrahydropyran. Figure-4 showed chromatographic analysis of various bioorganic compounds present in $N$. tabacum with respect to their different retention time and molecular weight.

\section{Discussion}

Phytochemical compounds such as terpenoids and alkaloids were known to possess insecticidal

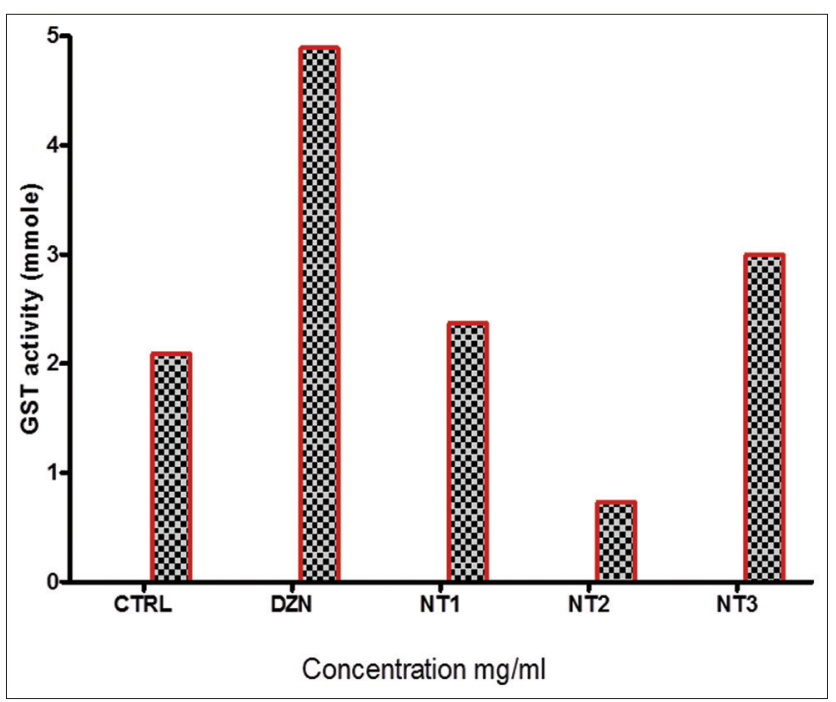

Figure-3: Tick glutathione S-transferase activity of Nicotiana tabacum. growth-inhibiting, anti-molting, and repellant activities [22]. The potential role of flavonoids in modulating the reproductive functions of ticks has been reported [23]. Alkaloid in the plant extracts was reported to cause mortality and inhibition of fecundity due to its neurotoxic properties [24]. Tannins have been reported to be useful in the treatment of Alzheimer and diabetes due to its hypoglycemic potential [25]. Nicotine is known to act as an agonist for the nicotine acetylcholine (nAch) receptor. Nicotine causes overstimulation of insect's nervous system resulting in intensive tremors, convulsions and then paralysis [26]. Pyridine, 3-(1-methyl-2-pyrrolidinyl)-, (S)- Nicotine is also used as agricultural pesticide [27]. Similarly, Phytol is a potent repellant against Anopheles gambiae [28]. Citronellol propionate is a common constituent of some oils reported to have high repellant properties against various insects [29]. Lavandulyl acetate and bicyclogermacrene were reported as larvicidal agents against three important mosquito vectors [30]. From this study, it is, therefore, reasonable to infer that nicotine affinities for insect's nAch receptor and additive action of bioactive components have a synergistic effect in tick mortality and inhibition of oviposition. Higher activity of tick GST in DZNtreated group compare to varying concentration of $N$. tabacum is an indication that DZN-treated group is prone to tick resistance which was corrected by $N$. tabacum, especially the NT2 at $0.06 \mathrm{mg} / \mathrm{ml}$ [31]. The presence of bioorganic compounds such as Pyridine, 3-(1-methyl-2-pyrrolidinyl)-, (S)- Nicotine, Citronellyl propionate, Crotonaldehyde, Lavandulyl acetate, trans-Phytol and Amitrole (3-Amino-1, 2, 4-triazole) revealed by GC-MS analysis of N-hexane leaves extract of $N$. tabacum possibly contributed to its potential acaricidal property.

\section{Conclusion}

Based on the results of this study, it can be concluded that leaf extract of $N$. tabacum from different regions within Oyo state, Nigeria, has potential acaricidal activity against the larvae and adult female ticks: $R$. sanguineus. N-hexane leaf extract

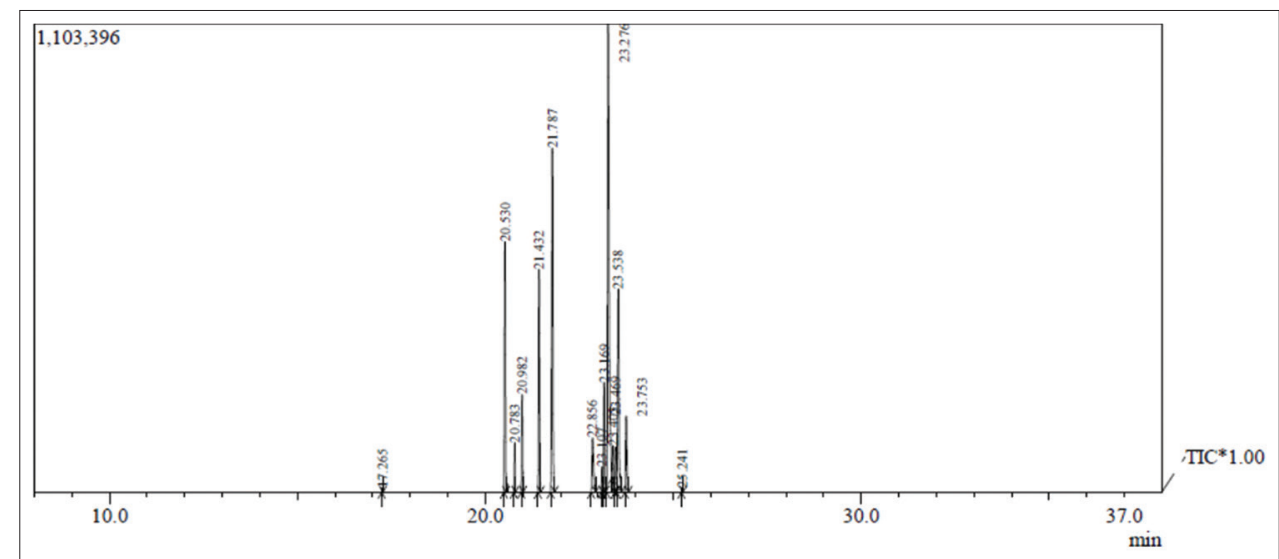

Figure 4: Chromatographic analysis of Nicotiana tabacum. 
of $N$. tabacum showed maximum efficacy in various stages of $R$. sanguineus. It is an indication that the non-polar compounds within the N-hexane leaf extract are responsible for acaricidal activity of this plant extract. The mechanism of acaricidal resistance of this novel plant was reported for the $1^{\text {st }}$ time. Possible side effects, especially at the experimental lethal dose of $N$. tabacum against $R$. sanguineus, are under investigation.

\section{Authors' Contributions}

JOA conceived and designed the plan of research work. TOO carried out the laboratory work and analyzed the results. AA performed the GC-MS analysis; OOO edited and made intellectual contribution to the manuscript. All authors read and approved the final manuscript.

\section{Acknowledgments}

The authors acknowledge the financial contribution of Postgraduate College, University of Ibadan towards the completion of this research work. Financial support received from the Cape Peninsula University of Technology (CPUTRJ23) and National Research Foundation (CPUT-NRF022) granted to Prof OO Oguntibeju is acknowledged.

\section{Competing Interests}

The authors declare that they have no competing interests.

\section{Publisher's Note}

Veterinary World remains neutral with regard to jurisdictional claims in published institutional affiliation.

\section{References}

1. ValcÁrcel, F., Sánchez, J.L., Jaime, J.M., Basco-Basco, P.I., Guajardo, S.C., Cutuli, M.T., GonzÁlez, J. and Olmeda, A.S. (2015) Control of tick infestations in Oryctolagus cuniculus (Lagomorpha: Leporidae) with spinosad under laboratory and field conditions. J. Med. Entomol., 52(2): 207-213.

2. Jongejan, F. and Uilenberg, G. (1994) Ticks and control methods. Rev. Sci. Tech. De Office Int. Des Epiz., 13(4): 1201-1226.

3. Asmaa, N.M. and El Bably, M. (2014) Studies on prevalence, risk indicators and control options for tick infestation in ruminants. Beni-Suef Univ. J. Basic Appl. Sci., 3(1): 2-7.

4. Abbas, R.Z., Zaman, M.A., Colwell, D.D., Gilleard, J. and Iqbal, Z. (2014) Acaricide resistance in cattle ticks and approaches to its management: The state of play. Vet. Parasitol., 203(1-2): 6-20.

5. Banumathi, B., Vaseeharan, B., Rajasekar, P., Prabhu, N.M., Ramasamy, P., Murugan, K., Canale, A. and Benelli, G. (2017) Exploitation of chemical, herbal and nanoformulated acaricides to control the cattle tick, Rhipicephalus (Boophilus) microplus a review. Vet. Parasitol., 244(2): 102-110.

6. Ishwarya, R., Vaseeharan, B., Kalyani, S., Banumathi, B., Govindarajan, M., Alharbi, N.S., Kadaikunnan, S., Al-Anbr, M.N., Khaled, J.M. and Benelli, G. (2017) Potential of traditional knowledge of plants in the management of arthropods in livestock industry with focus on (Acari) ticks. Evid. Based Complement. Alternat. Med.,
2017(2): 33 .

7. Baranitharan, M., Dhanasekaran, S., Gokulakrishnan, J., Babu, S.M. and Thushimenan, S. (2016) Nagapattinam medicinal plants against the dengue fever mosquito, Aedes aegypti. Int. J. Mosq. Res., 3(3): 29-34.

8. Koul, O. (2014) Botanical biopesticide approach in pest management: An Asian perspective. In: Saini, R.K., Yadav, G.S., Kumari, B., editors. Novel Approaches in Pest and Pesticide Management in Agro-ecosystem. Department of Entomology, CCS Haryana Agricultural University, Haryana. p200-213.

9. Makwali, J.A., Jumba, B.N., Choge, J.K., Adino, E.O. and Anjili, C.O. (2017) Experimental therapeutic assays of Tephrosia vogelii against Leishmania major infection in murine model: In vitro and in vivo. BMC Res Notes, 10(1): 698 .

10. Ndava, J, Mapuwei, T.W. and Madoma, C. (2018) A comparative assessment of the acaricidal activity of Tephrosia vogelii on Rhipicephalus appendiculatus and Amblyomma variegatum in Makoni district, Manicaland province, Zimbabwe. J. Entomol. Zool. Stud., 6(1): 1145-1150.

11. Yessinou, R.E., Adinci, J., Sessou, P., Adehan, S., Tonouweha, A. and Akpo, Y. (2016) In vitro acaricidal effect of Syzygium aromaticum and Cymbopogon citratus essential oils on engorged female of cattle tick Rhipicephalus microplus in Benin. Sci. J. Vet. Adv., 5(3): 80-86.

12. Hollingsworth, C.S. (2014) Pacific Northwest Insect Management Handbook. Oregon State University Corvallis, Washington.

13. Dipeolu, O.O. and Ndungu, J.N. (1991) Acaricidal activity of kupetaba ground-mixture of natural products against Rhipicephalus appendiculatus. Vet. Parasitol., 38(4): 327-338.

14. Ghosh, S., Tiwari, S.S., Kumar, B., Srivastava, S., Sharma, A.K., Kumar, S., Bandyopadhay, A., Julliet, S., Kumar, R and Rawat, A.K.S. (2015) Identification of potential plant extracts for anti-tick activity against acaricide resistant cattle ticks, Rhipicephalus (Boophilus) microplus. Expl. Appl. Acarol., 66(1): 159-171.

15. Chen, Z. (2014) Studies on the acaricidal mechanism of the active components from neem (Azadirachta indica) oil against Sarcoptes scabiei var. cuniculi. Vet. Parasitol., 204(3-4): 323-329.

16. Gebhardt, C. (2016) The historical role of species from the Solanaceae plant family in genetic research. Theor. Appl. Genet., 129(12): 2281-2294.

17. Estrada-Pena, A., Bouattour, A., Camicas, J.L. and Walker, A.R. (2004) Ticks of Domestic Animals in the Mediterranean Region: A Guide to Identification of Species. University of Zaragoza, Zaragoza.

18. Organization for Economic Co-operation and Development. (2000) Guidance Document on the Recognition, Assessment and Use of Clinical Signs as Humane Endpoints for Experimental Animals Used in Safety Evaluation. Environmental Health Safety Monograph. Series on Testing and Assess. No. 19. Organization for Economic Co-operation and Development, Paris.

19. Lorke, D. (1983) A new approach to practical acute toxicity testing. Arch. Toxicol., 54(4): 275-287.

20. Habig, W.H., Pabst, M.J. and Jakoby, W.B. (1974) Glutathione-S transferases: The first enzymatic step in mercapturic acid formation. J. Biol. Chem., 249(22): 7130-7139.

21. Ghosh, S. and Azhahianambi, P. (2007) Laboratory rearing of Theileria annulata free Hyalomma anatolicum anatolicum ticks. Exp. Appl. Acarol., 43(1): 137-146.

22. Sharma, I., Parashar, B., Vatsa, E., Chandel, S. and Sharma, S. (2016) Phytochemical screening and anthelmintic activity of leaves of Cedrus deodara (Roxb.). World J. Pharm. Pharm. Sci., 5(8): 1618-1628.

23. Guilherme, E., Riad, N., Antonio, D., Edna, F., Mateus, L., Ingrit, E., Maria, M., Suzana, P. and Ivana, B. (2012) Toxicity of Ipomoea alba. Pharmacol. Online, 3(1): 29-41. 
24. Valduga, A.T., Gonçalves, I.L., Magri, E. and Finzer, J.R.D. (2018) Chemistry, pharmacology and new trends in traditional functional and medicinal beverages. Food Res. Int., 120(5): 478-503.

25. Yatoo, M.I., Saxena, A., Gopalakrishnan, A., Alagawany, M. and Dhama, K. (2017) Promising antidiabetic drugs medicinal plants and herbs. Int. J. Pharmacol., 13(7): 732-745.

26. Madhukar, B.D., Sangram, H.P. and Chetan, S.S. (2012) Synthesis and insecticidal activity of some nicotinic acid derivatives. J. Chem. Pharmacol. Res., 4(1): 326-332.

27. Hukkanen, J., Jacob, P. and Benowitz, N.L. (2005) Metabolism and disposition in kinetics of nicotine. Int. J. Biochem. Res. Rev., 14(2): 1-9.

28. Gnankiné, O. and Bassolé, I.H. N. (2017) Essential oils as an alternative to pyrethroids' resistance against Anopheles species complex Giles (Diptera: Culicidae). Molecules, 22(10): 1321.
29. Giatropoulos, A., Kimbaris, A., Michaelakis, A., Papachristos, D.P., Polissiou, M.G. and Emmanouel, N. (2018) Chemical composition and assessment of larvicidal and repellent capacity of 14 Lamiaceae essential oils against Aedes albopictus. Parasitol. Res., 117(6): 1953-1964.

30. Govindarajan, M. and Benelli, G. (2016) Eco-friendly larvicides from Indian plants: Effectiveness of lavandulyl acetate and bicyclogermacrene on malaria, dengue and Japanese encephalitis mosquito vectors. Ecotoxicol. Environ. Saf., 133(3): 395-402.

31. Fular, A., Sharma, A.K., Kumar, S., Nagar, G., Chigure, G., Ray, D.D. and Ghosh, S. (2018) Establishment of a multi-acaricide resistant reference tick strain (IVRI-V) of Rhipicephalus microplus Ticks. Tick Borne Dis., 9(5): 1184-1191.

$* * * * * * * *$ 